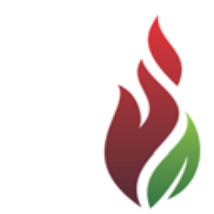

SUSTENERE

Publishing Corporation

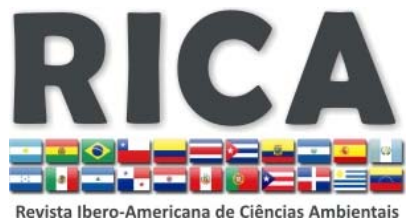

Journals Homepage:

www.sustenere.co/journals

\section{CORRELAÇÃO ENTRE PRECIPITAÇÃO PLUVIOMÉTRICA E UMIDADE DO SOLO NA PRODUÇÃO DE SERAPILHEIRA EM CAXIUANÃ (PA)}

\section{RESUMO}

Este trabalho teve como objetivos analisar a produção de serapilheira fina, bem como observar sua correlação com a precipitação pluviométrica e umidade do solo na Floresta Nacional de Caxiuanã-PA, no município de Melgaço, Pará, no período de janeiro de 2009 a dezembro de 2010. As coletas de serapilheira fina foram obtidas a cada quinze dias através de coletores. A produção de serapilheira fina apresentou uma correlação de nível moderada, negativa com a precipitação e umidade do solo, sendo observados os maiores valores de produção na área de floresta natural(Torre). As folhas mostraram-se como a principal componente de serapilheira fina para as duas áreas de estudo com aproximadamente $77 \%$ da produção total, seguidos de galhos com $13 \%$, frutos com $5 \%, 4 \%$ para flores e $1 \%$ para miscelâneas. Notou-se uma influência bastante significativa, do tipo de solo na produção de serapilheira, além dos efeitos do fenômeno de escala global EL NIÑO, na produção da mesma.

PALAVRAS-CHAVES: Florestas; Liteira; Chuva.

\section{CORRELATION BETWEEN RAINFALL AND SOIL MOISTUREIN LITTER PRODUCTION IN CAXIUANÃ-PA}

\section{ABSTRACT}

This study aimed to analyze the production of fine litter and observe its correlation with rainfall and soil moisture in Caxiuanã National Forest, in the municipality of Melgaço, Pará, from January 2009 to December 2010. The fine collection of litter were collected every fortnight by collectors. Litter production thin level showed a moderate correlation, negative correlation with precipitation and soil moisture, with the highest values in the areas of production and Tower black land. The leaves were the main component of litter fine for all areas of study with approximately $77 \%$ of total production, followed by branches with $13 \%, 5 \%$ fruits, flowers and $4 \%$ to $1 \%$ for miscellaneous. Noticed a very significant influence, especially in the area of exclusion of water, the effects of the phenomenon of global EL NIÑO in litter production.

KEYWORDS: Forests; Litter; Rain.
Revista Ibero-Americana de

Ciências Ambientais, Aquidabã, v.5, n.1, Dez 2013, Jan, Fev, Mar, Abr, Mai 2014.

ISSN 2179-6858

\section{SECTION: Articles}

TOPIC: Mudanças Climáticas Globais

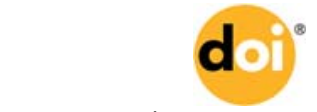

DOI: 10.6008/SPC2179-6858.2014.001.0012

Maurício Castro da Costa

Universidade Federal do Pará, Brasil http://lattes.cnpq.br/6033026062600712 hidromau@bol.com.br

Antonio Carlos Lôla da Costa Universidade Federal do Pará, Brasil http://lattes.cnpq.br/8489039131103228 lola@ufpa.br

Lana Tais da Silva Coelho Instituto de Estudos Superiores da Amazônia, Brasil http://lattes.cnpq.br/1843273611069528 laninhacoelho11@hotmail.com

Thamna Maíra Lourinho Silva Instituto de Estudos Superiores da Amazônia, Brasil http://lattes.cnpq.br/4924385481057859 thamna maira@hotmail.com

Antônio Ferreira Azevedo Instituto Nacional de Pesquisas da Amazônia, Brasi http://lattes.cnpq.br/3230683085377559 antonio.azevedo@yahoo.com.br

Received: 15/11/2013 Approved: 15/05/2014 Reviewed anonymously in the process of blind peer.

\section{Referencing this:}

COSTA, M. C.; COSTA, A. C. L.; COELHO, L. T. S.; SILVA, T. M. L.; AZEVEDO, A. F.. Correlação entre precipitação pluviométrica e umidade do solo na produção de serapilheira em Caxiuanã (PA). Revista lbero-

Americana de Ciências Ambientais, Aquidabã, v.5, n.1, p.170-179, 2014. DOI:

http://dx.doi.org/10.6008/SPC21796858.2014 .001 .0012 


\section{INTRODUÇÃO}

Um ecossistema pode ser definido como o sistema de interações entre uma comunidade de organismos e seu meio ambiente. Estão envolvidos nesta interação o ciclo de minerais, o fluxo de energia e a dinâmica das populações (ODUM, 1988).

As florestas tropicais são ecossistemas de alta produtividade. Nelas boa parte da energia e nutrientes absorvidos é direcionada para a manutenção e crescimento das estruturas do dossel das árvores (galhos, folhas, flores e frutos). Como as árvores periodicamente substituem estas estruturas devido a fatores evolutivos ou como resposta a tensões ambientais, coletar e pesar estes materiais após sua queda é uma forma não destrutiva de estimar a produtividade destes ecossistemas, uma vez que podem representar até $90 \%$ da produção primária líquida (MORAES et al., 1996; CLARK et al., 2001). Este material vegetal que cai constantemente sobre o solo (folhas, ramos, flores, frutos, e fragmentos de casca) e, em menor proporção o de origem animal (insetos, restos animais e material fecal) é denominado chuva de serapilheira, leiteira, folhedo ou litter (DINIZ \& PAGANO, 1997).

A serapilheira é o conjunto de detritos orgânicos, principalmente de origem vegetal, produzidos pela floresta (folhas, gravetos e galhos, flores e frutos, e outros componentes menores). Uma série de fatores bióticos e abióticos influencia na produção de serapilheira, como por exemplo, a latitude, altitude, temperatura do ar, precipitação, estágio sucessional, herbívora, disponibilidade hídrica e estoque de nutrientes do solo (PORTES et al., 1996), umidade do solo (BURGHOUTS et al., 1994) e vento (DIAS \& OLIVEIRA FILHO, 1997).

A serapilheira quando acumulada sobre o solo contribui, juntamente com os diversos compartimentos florestais, para a interceptação das gotas de chuva, minimizando assim seus efeitos erosivos. É também um compartimento de armazenamento de água, que apesar de pouca capacidade em termos quantitativos, funciona como um isolante térmico, contribuindo para a redução da evaporação e manutenção de um micro clima estável na superfície do solo (KINDEL, 2001).

A deposição da serapilheira representa do ponto de vista do indivíduo, uma perda considerável de energia e de nutrientes (DELLITI, 1995). Além disto, grande parte das florestas tropicais está situada em solos antigos pré-cambrianos, altamente lixiviados ou sobre depósitos arenosos pobres em nutrientes.

A estrutura de maior importância para a retenção de nutrientes pelo ecossistema florestal é o tapete formado por serapilheira e raízes finas, muitas vezes associadas a fungos micorrízicos que cobre o solo florestal. As raízes absorvem os nutrientes diretamente das folhas e da fauna saprófita em decomposição e penetram também a primeira camada do solo, minimizando a lixiviação causada pelas fortes chuvas tropicais. (VITOUSEK, 1984; GONÇALVEZ \& MELLO, 2000). 
As diferentes frações de serapilheira apresentaram distintas taxas de mineralização, onde a produção de folhas aparece como a mais notória e importante. Assim, esse estudo tem como objetivo quantificar a produção de serapilheira fina, bem como mostrar a relação entre a produção desse parâmetro, com a precipitação pluviométrica e umidade do solo à superfície no período de janeiro de 2009 a dezembro de 2010.

\section{METODOLOGIA}

A Estação Científica Ferreira Penna, que serve como base para as pesquisas realizadas na área da Floresta Nacional de Caxiuanã, foi criada pelo decreto lei $n^{\circ} 194$, de 22 de novembro de 1961. Está localizada no Estado do Pará, ocupando área de 324.060 hectares, nas proximidades da baía de Caxiuanã, entre os rios Xingu e Tapajós. Corresponde a aproximadamente $70 \%$ do município de Portel e $30 \%$ do município de Melgaço e está distante cerca de 400 km a Oeste da cidade de Belém, capital do Estado do Pará. Esta região possui alguns dos ecossistemas naturais mais representativos da Amazônia, como florestas de terra firme, igapó e várzeas. (COSTA et al., 2003).

Segundo Köppen o clima da Floresta Nacionalde Caxiuanã é do tipo tropical quente e úmido e subtipo "Am" com curta estação seca entre agosto e novembrō. A temperatura média do ar é de $26,7^{\circ} \mathrm{C}$, com mínimas de de $22,0^{\circ} \mathrm{C}$ e máximas de $32,0^{\circ} \mathrm{C}$ (COSTA et al., 2003). brilhode luz solar alcança cerca de 2100 horas ano-1, com média anual de umidade relativa do ar em torno de $92,2 \%$, com menores valores de umidade relativa sendo encontrados no período seco da região, com valor de $70 \%$. A direção predominante do vento é de nordeste - sudeste, apresentando velocidade média de $0,9 \mathrm{~m} / \mathrm{s}$ (COSTA et al., 2003).

A região de Caxiuanã apresenta sazonalidade das chuvas bem definida, com distribuição regular, porém divididas em dois períodos distintos. Climatologicamente, o período chuvoso está compreendido de dezembro a junho, enquanto o período seco vai de agosto a novembro. A média anual climatológica da chuva na Floresta Nacional de Caxiuanã é de 2.011,2 mm. Essa floresta agrega vários ecossistemas, dentre eles a floresta densa de terra-firme, várzeas e igapós (ALMEIDA et al,. 1993). Os solos são bem a moderadamente drenados, arenosos a argilosos, ácidos e pobres em nutrientes, apresentando $\mathrm{pH}$ muito ácido $(3,5)$ a moderadamente ácido $(5,5)$, (RUIVO et al,. 2002).

A área de Terra Preta estudada na Floresta Nacional de Caxiuanã corresponde a um hectare de floresta secundária de terra firme, dividida em 25 subparcelas de $20 \mathrm{~m}$ por $20 \mathrm{~m}$. Está localizada às margens da baía de Caxiuanã, na área de proteção do IBAMA, onde é conhecido popularmente como área "Manduquinha", nome relacionado a um antigo morador da área.

Essa área apresenta textura variando de franco arenoso, nos primeiro $5 \mathrm{~cm}$ a franco argilo arenosa até $50 \mathrm{~cm}$, apresentando maiores teores de silte em relação a outra área. Apresenta 
valores de $\mathrm{pH}$ com nível moderadamente ácidos, em torno de 6,13 diminuindo essa acidez com a profundidade (RUIVO 2001).

Essa áreaapresenta solo com boa drenagem e coloração do solo escurecido, resultado da concentração de substâncias orgânicas depositadas no solo, apresentando altos teores de cálcio, carbono, magnésio, manganês, fósforo e zinco, elementos que tornam o solo com fertilidade diferenciada, quando comparadas a outros solos amazônicos.

A área Torre corresponde a uma área de um hectare de floresta primária, intácta, aqual está dividida em 25 sub parcelas de $20 \mathrm{~m}$ por $20 \mathrm{~m}$. Nesta área fica localizada uma torre de observação micrometeorológica do projeto LBA, motivo pela qual recebeu o nome. Apresenta menor quantidade de árvores por hectare, porém a mesma apresenta indivíduos com maior concentração de biomassa nos troncos, além de um melhor arranjo na estrutura do dossel.

O solo dessa área é classificado por Ruivo (2001), como Latossolo Amarelo, moderadamente drenado, cor bruno amarelo escuro a vermelho amarelado, com textura de média a muito argiloso, caracterizando-o como argilo arenoso, tornando-o imperfeitamente drenado.

As coletas de serapilheiras finas foram feitas quinzenalmente, no período de janeiro de 2009 a dezembro de 2010. Utilizando-se 25 coletores por área de estudo. Os coletores eram formadas de malha de nylon de $1 \mathrm{~mm}$, com área individual de $0,25 \mathrm{~m}^{2}$ para as áreas estudadas, distribuidos em espaço alternados a uma altura de $50 \mathrm{~cm}$ acima do solo.

O recolhimento do material foi feito em sacos de papel, sendo levados ao laboratório para uma minunciosa triagem, sendo selecionados em componentes: folhas, galhos, flores, frutos e miscelânias, com até $2 \mathrm{~cm}$ de diâmetro. Este material foi colocado para secar em estufa a $80^{\circ} \mathrm{C}$ até obtenção dopeso constante. Após secagem, as frações foram pesadas em balança de precisão para determinação de massa seca.

A precipitação pluviométrica foi obtida através da utilização de um pluviógrafo do tipo CSI Model CS700-L Rain Gage, com 200 mm de diâmetro de funil e capacidade de "basculante" $100 \mathrm{~mm} /$ hora instalado em uma torre micro meteorológica de alumínio, com 42 metros de altura, com aproximadamente 3.000 metros da área Torre e 15000 metros da área Terra Preta. A umidade do solo à superfície foi obtida através de um CS-620 HYDROSENSE Soil, onde se utilizou de médias mensais de 25 pontos próximos aos coletores de serapilheira contidos em cada área.

Análises de correlação linear foram utilizadas para se avaliar a influência de uma única variável (precipitação pluviométrica, umidade do solo à superfície), na produção de serapilheira fina. Utilizou-se para isso o programa estatístico "R", para aplicação de medidas de tendência central, medidas de dispersão, correlação linear simples e teste de significância, além de representação gráfica. Também se utilizou para a geração de gráficos o software Microsoft Excel (2010). Como parâmetro de interpretação do coeficiente de Pearson (r), ou coeficiente de correlação, foi utilizada a metodologia proposta por Shimakura (2006). 


\section{RESULTADOS}

Notou-se que na distribuição mensal da precipitação pluviométrica relacionada com a umidade do solo à superfície que ocorreu uma tendência de correlação direta de nível fraco entre os dois parâmetros estudados, onde os maiores valores de umidade do solo à superfície são observados no período chuvoso da região, ocorrendo o inverso para o período seco, com exceção da área de Terra Preta que não apresentou correlação significativa entre os parâmetros, com nível de significância $P<0,05$.

A Figura 01, apresenta a distribuição da precipitação pluviométrica relacionada com a umidade do solo à superfície no período de 2009 a 2010, nas duas áreas estudadas na Floresta Nacional de Caxiuanã-PA. Observou-se um maior volume de chuvas no ano de 2009 , com valor de 2.281,3 mm, próximo a normal climatológica da região que é em torno de 2011,2 mm. O ano de 2010 apresentou um volume de 1.586,8 mm, abaixo da normal climatológica, mostrando uma redução no volume de chuva de aproximadamente $30,4 \%$ com relação ao ano anterior.

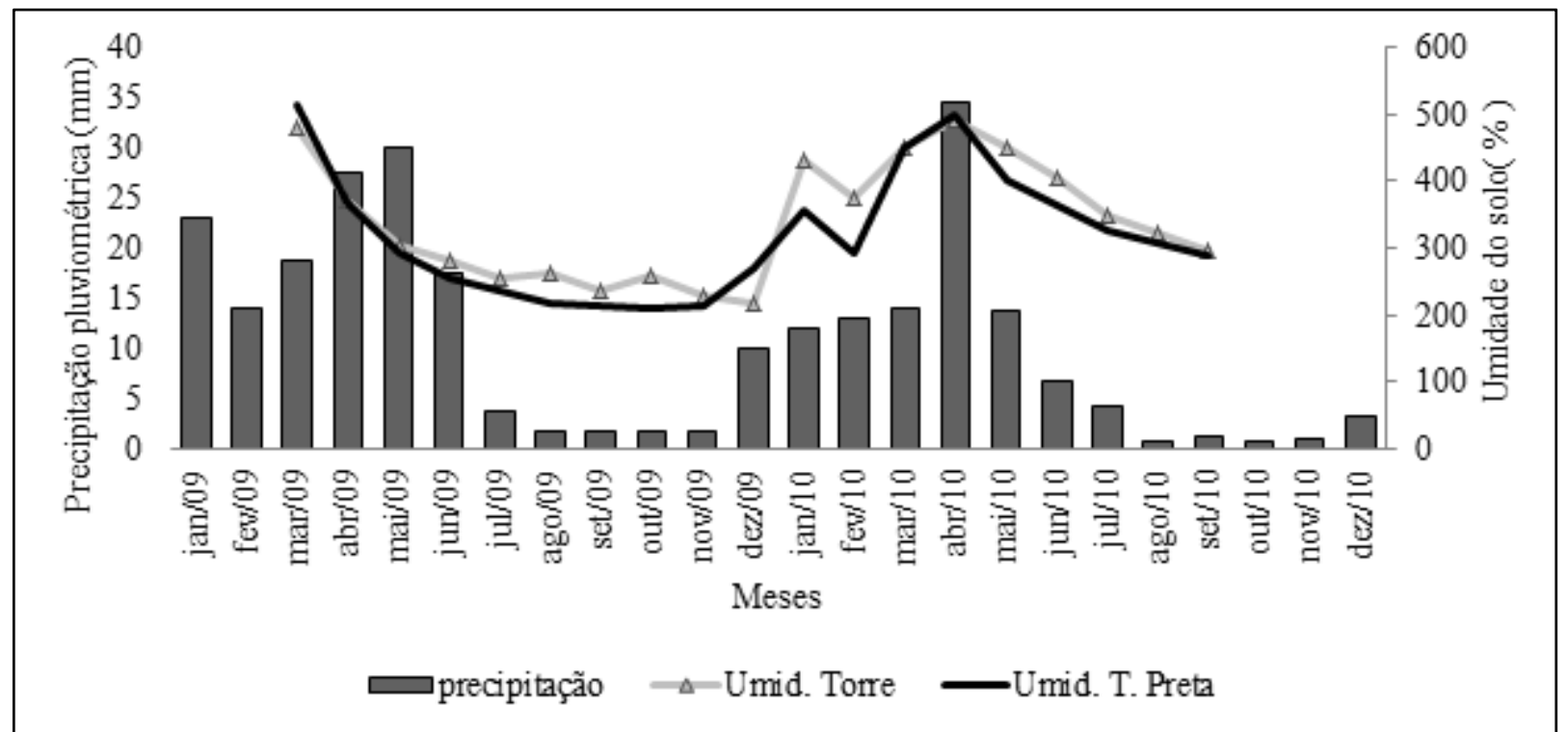

Figura 01: Distribuição da precipitação pluviométrica relacionada com a umidade do solo à superfície no período de 2009 a 2010, nas duas áreas estudadas na Floresta Nacional de Caxiuanã-PA.

O ano de 2009 apresentou características próximas à normalidade climatológica da região, onde o período chuvoso estendeu-se de janeiro a maio, apresentando junho e julho como período de transição e o período menos chuvoso ocorrendo de agosto a dezembro. O ano de 2010 apresentou maior irregularidade, com volume menor de chuvas principalmente no período chuvoso da região.

Os valores de umidade do solo à superfície foram observados com maior magnitude na área Torre do que na área de Terra Preta.

A Tabela 01 mostra a produção anual de serapilheira fina para o período estudado nas duas áreas da Floresta Nacional de Caxiuanã-PA. Notou-se que nesse periodo os maiores valores na produção total de serapilheira fina foram encontrados na área Torre. 
Tabela 01: Produção média anual de serapilheira fina em Mg.ha..$^{-1} \cdot$ ano $^{-1}$, no período de 2009 a 2010, nas duas áreas estudadas na Floresta Nacional de Caxiuanã-PA.

\begin{tabular}{ccc}
\hline Área & Torre & T. Preta \\
\hline $\mathbf{2 0 0 9}$ & 6,03 & 5,00 \\
$\mathbf{2 0 1 0}$ & 8,50 & 6,19 \\
Total & 14,53 & 11,19 \\
Aumento 2009/2010 & $30 \%$ & $19 \%$ \\
\hline
\end{tabular}

Notu-se um aumento significativo na produção de serrapilheira fina nas duas áreas entre os anos de 2009 e 2010 de cerca de aproximadamente 30 e 19\% para as áreas da Torre e Terra Preta respectivamente.

A produção mensal de serapilheira fina respondeu ao regime de precipitação pluviométrica da região de maneira indireta, ocorrendo uma correlação inversa para as duas áreas estudadas, ou seja, os maiores valores na produção de serapilheira fina se deram no período de menor volume de chuvas para as áreas. Essas correlações apresentaram nível moderadas, mostrando variâncias significativas com valores de $p<0,01$, onde 42 e $61 \%$ das variações na produção de serapilheira fina seriam explicados pela variação da precipitação pluviométrica nas áreas Torre e Terra Preta respetivamente.

A Figura 02 mostra a distribuição mensal da produção de serapilheira fina das duas áreas relacionada com a precipitação pluviométrica. Observou-se que a produção de serapilheira fina apresentou-se ininterrupta durante todo o ano, mostrando-se bem relacionada com a sazonalidade das chuvas da região. Os maiores valores foram observados no período menos chuvoso, declinando conforme a chegada do período mais chuvoso.



Figura 02: Distribuição mensal da produção de serapilheira fina relacionada com a precipitação pluviométrica no período de 2009 a 2010 nas duas áreas na Floresta Nacional de Caxiuanã-PA.

A Figura 03 mostra a distribuição mensal da produção de serapilheira fina com a umidade do solo à superfície nas duas áreas. Observou-se que a área Terra Preta apresenta uma 
configuração de produção bem mais definida com o parâmetro estudado, mostrando uma correlação inversa de nível fraco com da variação na produção de serapilheira da ordem de $29 \%$. $\mathrm{Na}$ área Torre não foi observada correlação significativa entre os parâmetros, apesar de apresentar os maiores valores de umidade no solo dentre as áreas, principalmente no período menos chuvoso.

Figura 03: Distribuição média mensal da produção de serapilheira fina relacionada com a umidade do solo

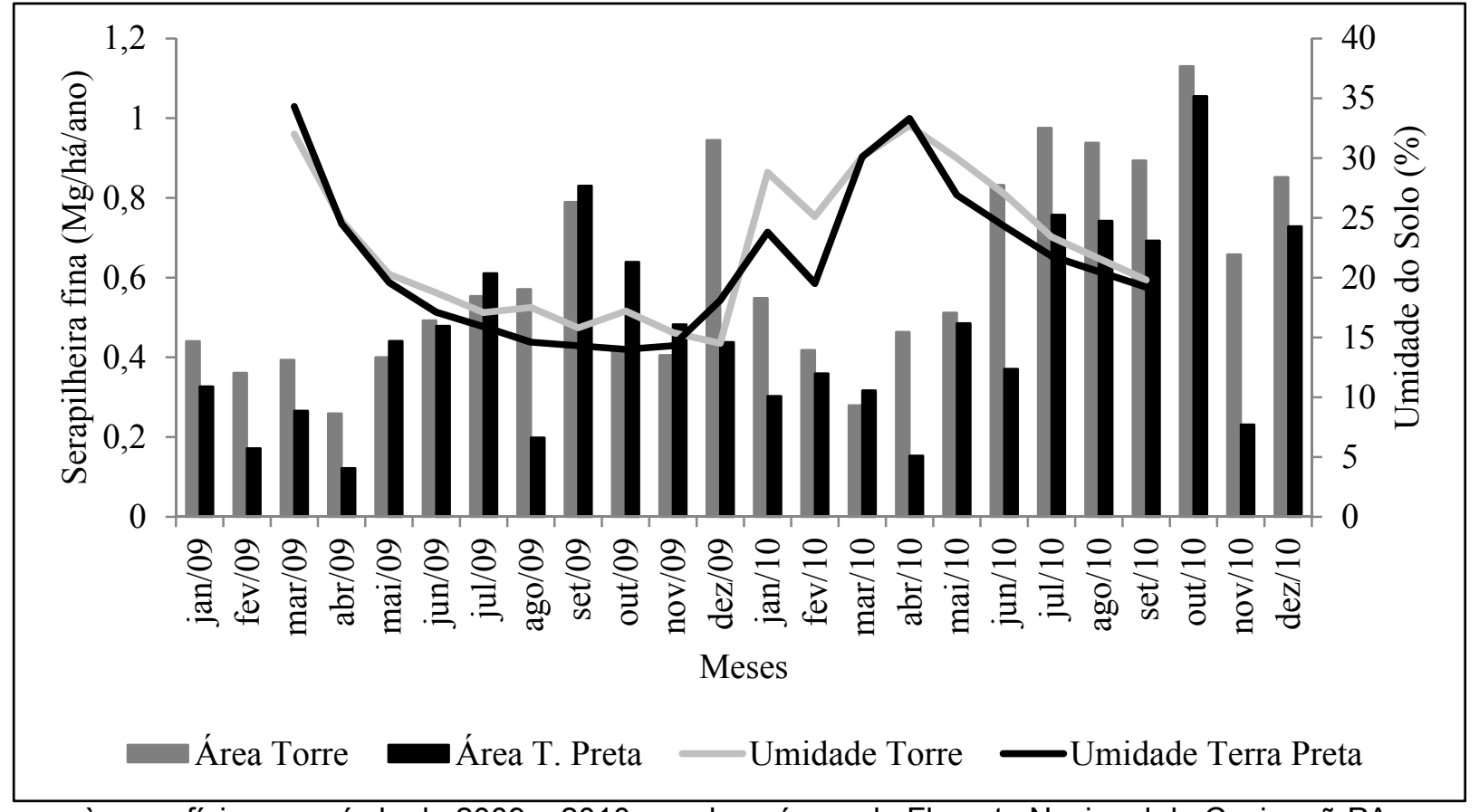

à superfície no período de 2009 a 2010 nas duas áreas da Floresta Nacional de Caxiuanã-PA.

\section{RESULTADOS E DISCUSSÃO}

A distribuição mensal da precipitação pluviométrica relacionada com a umidade do solo à superfície pode ter apresentado correlação direta de nível fraco entre os dois parâmetros estudados, na área da Torre, devido esta apresentar-se mais distante do ponto de coleta de chuva, além da área de Terra Preta apresentar-se localizada às margens da Baia de Caxiuanã, o que lhe rendeu correção não significativa.

A distribuição da precipitação pluviométrica relacionada com a umidade do solo à superfície no período de 2009 a 2010 ocorreu devido à atuação do fenômeno EL NIÑO, que é um fenômeno de escala global que tende a inibir as chuvas na região amazônica. Esse fenômeno apesar de ter sido detectado em 2009 só foi sentido seus efeitos em 2010.

Os valores mais elevados de umidade do solo à superfície observados na área Torre estão relacionados às características da textura do solo dessa área, a qual se apresenta com alto teor de argila, tornando ineficiente a drenagem da água das chuvas.

Os maiores valores de umidade do solo à superfície observados na área Torre pode estar relacionado com o arranjo do dossel dessa área, onde se apresenta mais fechado e com maior diversidade de vegetação. Essa área apresenta número considerável de espécies com estratos 
mais bem estruturados, além de maior número de indivíduos na classe de maiores diâmetros a altura do peito (DAP), quando comparados à área de Terra Preta. Os menores valores de produção na área Terra Preta ocorreram devido a maior dinâmica que existe numa área de floresta secundária na produção de biomassa de troncos e de raizes diferentes da dinâmica de uma floresta primária, além da grande frequência de indivíduos com características bem peculiáres de floresta de capoeira. Um fator favorável a produção de serapilheira fina nessa área pode ser a proximidade com a baía de Caxiuanã que a torna mais sujeita a efeitos de brisas.

O aumento significativo na produção de serrapilheira fina nas duas áreas entre os anos de 2009 e 2010 é explicado pela redução significativa na precipitação pluviométrica da região neste período, ocasionado pelo fenômeno EI NIÑO, atuante no ano de 2010. Estudos relataram resultados semelhantes a este em florestas com estádios sucessionais na Amazônia como Luizão (1982); Dantas (1986); Martius et al. (2004)

Valores semelhantes ao encontrado neste estudo foram verificados por Teixeira et al (2001), na mesma região em floresta primária e secundária, com médias de 5,8 Mg. ha. ${ }^{-1}$.ano-1 e 3,8 Mg.ha.-1.ano-1respectivamente. Silva, (1982),estudando a produção de serapilheira em florestas de terra firme encontou valor de 7,3 Mg. ha. ${ }^{-1} \cdot \mathrm{ano}^{-1}$, sendo que a sazonalidade ficou marcante em todos esses estudos.

A diferença entre a qualidade de correlação existente entre a produção mensal de serapilheira fina e o regime de precipitação pluviométrica da região nas diferentes áreas pode está relacionada à distância existente entre o ponto de coleta de precipitação pluviométrica e as áreas, além da distinção na composição física do solo entre as mesmas.

Os dados de distribuição mensal da produção de serapilheira fina com a umidade do solo à superfície na área de Terra Preta pode ter ocorrido devido esta área apresentar maiores variações na produção de serapilheira no decorrer do período, tendo em vista que se trata de uma área em recuperação. A correlação inversa observada nessa área é perfeitamente compreendida, pois as espécies vegetais no início do período seco se utilizam de estratégias evolutivas, sendo forçadas a liberarem serapilheira para aproveitarem a umidade ainda existente no solo e a proliferação de organismos decompositores que acelerarem o processo de ciclagem de nutrientes, que é o responsável pela manutenção de todo o processo biogeoquímico no ecossistema vegetal. Na área Torre o resultado é justificado devido a pouca variação no decorrer dos meses, além da composição argilosa do solo.

\section{CONCLUSÕES}

Os maiores valores de biomassa total de serapilheira fina foram observados na área Torre, seguido da área de Terra Preta, área $A$ e área $B$ respectivamente. A influência da precipitação pluviométrica e da umidade do solo à superfície na produção total de serapilheira fina foi bem evidenciada nas quatro áreas estudadas. 
A influência do fenômeno de grande escala ELNIÑO, reduzindo o volume de chuvas da região no ano de 2010, influenciou visivelmente para a variação da produção de serapilheira fina nas quatro áreas estudadas.

Ocorreu uma correlação inversa entre a precipitação pluviométrica e umidade do solo com a produção de serapilheira fina total para as áreas estudadas. O déficit hídrico, a diversidade nas espécies e as características do solo de cada área influenciaram significativamente na produção de biomassa total de serapilheira fina.

\section{REFERÊNCIAS}

ALMEIDA, S. S.; LISBOA, P. L. B.; SILVA, A. S. L.. Diversidade florística de uma comunidade arbórea na Estação Científica Ferreira Penna, Caxiuanã, Pará. Boletim Museu Paraense Emílio Goeldi, série botânica, Belém, v.9, n.1, p.99-105, 1993.

BURGHOUTS, T. B. A.; CAMPBELL, E. J. F.; KODERMAN, P. J.. Effects of tree species heteregeneity of leaf fall in primary an logged dipterocarp forest in the UluSegana Forest Reserv, Sabah, Malasia. Journal of Tropical Ecology, v.10, p.1-26, 1994.

CLARK, A. D.; BROWN, S.; KICLIGHTER, D. W.; CHAMBERS, J. Q.; THOMLINSON, J. R.; NI, J.; HOLLAND, E. A.. Net primary production in tropical forests: an evaluation and synthesis of existing field data. Ecological Applications, v.11, n.2, p.371-384, 2001.

COSTA, A. C. L.. Variações sazonais dos componentes do balanço de radiação e energia na reserva florestal de caxiuanã. In: CONGRESSO BRASILEIRO DE AGROMETEOROLOGIA, 8. Anais. Santa Maria, 2003.

DANTAS, M.. Produção de "litter" e seu conteúdo de nutrientes em floresta primária e capoeira da Amazônia Oriental. In: EMBRAPA/CPATU. Pesquisas sobre utilização e conservação do solo na Amazônia Oriental; relatório final do convênio EMBRAPA/CPATU-GT, Belém, 1986.

DELLITI, W. B. C.. Estudos de ciclagem de nutrientes: instrumentos para a análise funcional de ecossistemas terrestres. Oecologia Brasiliensis, v.1, p.469-486, 1995.

DIAS, H. C. T.; OLIVEIRA FILHO, A. T.. Variação temporal e espacial da produção de leiteira em uma área de Floresta Estacional Semidecídua Montana em Lavras-MG. Revista Árvore, v. 21, n. 1, p. 11-26, 1997.

DINIZ, S.; PAGANO, S. N.. Dinâmica de folhedo em floresta mesófila semidecídua no Município de Araras, SP - Produção, decomposição e acúmulo. Rev. Inst. Flor., v. 9, n. 1, p. 27-36, 1997.

GONÇALVEZ, J. L. M.; MELLO, S. L. M.. O sistema radicular das árvores. In:Nutrição e fertilidade florestal. Piracicaba: IPET, 2000.

KINDEL, A.. A fragmentação real: heterogeneidade de remanescentes florestais e valor indicador das formas de húmus. Tese (Doutorado em Geografia) - Universidade Federal do Rio de Janeiro, Rio de Janeiro, 2001.

LUIZÃO, F. J.. Produção e decomposição da liteira em floresta de terra firme da Amazônia Central: aspectos químicos e biológicos da lixiviação e remoção dos nutrientes da liteira. Dissertação (Mestrado) INPA/UFAM, Manaus, 1982.

MARTIUS, C.; HOFER, H.; GARCIA, M. V. B.; ROMBKE, J.; HANAGARTH, W.. Litter fall, litter stocks and decomposition rates in rainforest and agroforestry sites in Central Amazônia. Revista NutrientCycling in Agroecosystems, v.68, p.137-154, 2004.

MORAES, R. M.. Ciclagem mineral em mata atlântica de encosta e mata sobre restinga, llha do Cardoso, SP; nutrientes na serapilheira acumulada. In: Simpósio de Ecossistemas Brasileiros, 6. Anais. São Paulo: ACIESP, 1996. 
ODUM, E. P.. Ecologia. 4 ed. Rio de Janeiro: Guanabara, 1988.

PORTES, M. C. G. O.; KOEHLER, A.; GALVÃO, F.. Variação Sazonal de deposição de leiteira em uma Floresta Ombrófila densa Altomontana no morro do Anhangava. Floresta, v.26, p.3-10, 1996.

RUIVO M. L. P.; PEREIRA S. B.; BUSETTI E. P. C.; COSTA, F. R.; QAUNZ, B.; NAGAISHI, T. Y.; MEIR P.; MAHLI Y.; COSTA, A.. Variações no solo no fluxo de CO2 nos sítios do Esecaflor (Caxiuanã, Pará). In: SBG, SIMPÓSIO DE GEOLOGIA DA AMAZÔNIA, 7, Anais. Belém, 2007.

SHIMAKURA, S.. Departamento de Estatística UFPR. CE003 - Estatística II, 2006.

SILVA, M. F. F.. Produção anual de liteira e seu conteúdo mineralógico em mata tropical de terra firme na área do Rio Tocantins, Pará. Dissertação (Mestrado) - Fundação Universidade Federal do Amazonas, Manaus, 1982.

TEIXEIRA, L. B.; OLIVEIRA, R. F.; MARTINS, P. F.. Ciclagem de nutrientes através da liteira em floresta, capoeira e consórcios com plantas perenes. Revista Ciências Agrárias, v.36, p.91-99, 2001.

VITOUSEK, P. M.. Litterfal, nutrient cycling, and nutrient limitation in tropical forests. Ecology, v.65, n.1, p.285-298, 1984. 